\title{
Productivity Measurement for the Anti-sliding Pile of Xiluodu Hydropower Project
}

\author{
Chen Zhiding ${ }^{*}$, Xiao Fang and Liu Hao \\ College of Hydraulic \& Environmental Engineering, China Three Gorges University, Yichang, Hubei, 443002, P.R. \\ China
}

\begin{abstract}
In recent decades, there has been a huge rise in the amount of investments and resources put into hydropower construction projects. Thereupon, it is becoming an urgent need to study how to estimate the input so as to control total cost effectively and utilize the resources adequately. With that in mind, this paper introduced the process of construction productivity determination for the anti-sliding pile of Xiluodu Hydropower Project, as a typically measured object. The determination work includes: choosing timing observation method to measure labor and machinery productivity; selecting real-time writing method to measure material productivity; then adopting probabilistic evaluation method to analyze the obtained data resulting from construction productivity; finally forming the consumption quota per unit pile length through comprehensive arrangement of the above steps. Significantly, the research conducted may provide a platform for both the related researchers and practitioners to appreciate the construction and measurement processes of the anti-sliding pile and may pave the way for builders and managers conducting similar projects in future to gain a clear understanding of the efficiency and cost control.
\end{abstract}

Keywords: Anti-sliding pile, measurement, productivity, xiluodu hydropower project.

\section{INTRODUCTION}

With the growing requirements for electricity, the past few decades have seen rapid development and expansion of the hydropower industry in our country. The number of constructed dams almost accounts for half of the total dams which exist in the world and the capital and resources are being increasingly invested in the hydropower construction projects. Thus, to study and solve the problem of how to effectively control the cost and save resource is an urgent matter, for the sake of hydropower project management. Significantly, the achievement of construction productivity, namely consumption quota, can help solve the problem. As a measure of the output of production factors over a defined period of time or a measure of how well the factors are utilized, construction productivity is the basis of determination of consumed labor, materials and machineries; it is a foundation of scheduling and cost prediction; moreover, it is an important tool to strengthen enterprise management for helping in economizing on input. The establishment work for construction productivity has made great achievements in recent years, involving an extensive scope and becoming more and more specific in the project items. However, with the expansion of hydro-power project scale and the increase in construction technology difficulties, the construction process has been improved and innovated, resulting in that the current quota cannot meet all the needs of actual productivity. To settle contradiction, actual late productivity should be measured to obtain production quota, especially the typical projects.

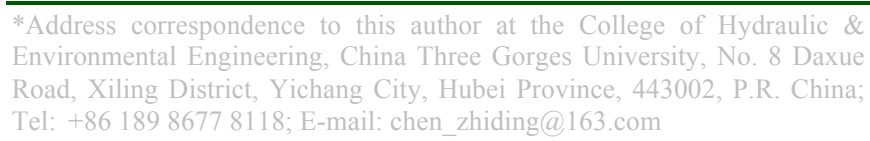

During the process of hydropower construction, the slope stability problems become more and more highlighted, augmenting dam height and complexity of geological conditions. Anti-sliding pile technology, as one of the main measures of slope anti-sliding reinforcement, has been rapidly improved and widely applied in the recent decades. The researches on the anti-sliding pile at home and abroad mainly focus on the design [1], structure calculation method [2] and reinforcement mechanism [3], and so on. Unfortunately, the research on the productivity and evaluation of anti-sliding pile is totally blank and has nocomplete valuation foundation, causing great difficulties for reasonably confirming and effectively controlling corresponding actual cost. To meet the management needs of projects adopting anti-sliding pile technology to stabilize the slope, on-site technical determination has been conducted at each main stage of the anti-sliding pile construction belonging to Xiluodu project, including pile holing and wall retaining, reinforcing cage binding and pile-core concrete pouring. Consequently, first-hand valuable technical and economic data have been acquired, and construction productivity can be obtained by compilation and reasonable analysis of the data.

Xiluodu hydropower station is a key project included in the national "tenth five-year" plan outline and approved by the Chinese State Council. It is located in the Jinsha River valley on the border of Leibo county of Sichuan province and Yongshan county of Yunnan province. The project is a large multi-purpose project with the main purpose of power generation combining silt arresting, flood control, log passing and navigation. Xiluodu project has various characteristics, such as high arch dam, high seismic intensity area, high slope, high water head, great discharge, large 
under-ground cavities and so on. The dam fortification parameter of high seismic intensity area is the highest in China; the high water head and large flood-discharge power are farbeyond the existing level of engineering at home and abroad; the large-scale underground caverns are the greatest in the world. The first set of generators of Xiluodu hydropower station produced electricity in June 2013 and the whole project was completed in 2015, the total time is about 13 years (AUTHOR: The highlighted number of years is vague and must be clarified) and static investment 50.342 billion RMB yuan, calculated according to the price levels in the first quarter of 2005 .

\section{METHODS}

\subsection{Productivity Determination Methods}

The key point of quota establishing is to ensure the fixed level, necessary to adhere to average advanced principle over a period of time, namely that most of the staff, under the same conditions, can achieve or surpass through the efforts. The core work of construction productivity determination is the consumption measurement of labor force, materials and machine-hour [4].

The productivity measurement of labor and machinery is mainly in regard to the consumed working time. The commonly-used methods of time measurement include timing observation method, analogy comparison method, and statistical analysis, etc. Among them, statistical analysis requires current statistics regarding time consumption of the past similar projects researched; analogy comparison method requires the productivity level of typical measure item of similar product or process as a standard to conduct comparative analysis. As there are no previous statistics and comparative standards for the anti-sliding pile of Xiluodu project, this determination evaluation adopted timing observation method to measure time consumption, and directly conducted timely research by intensive sampling and extensive sampling technologies and so on.

Combining actual situation of material used in this antisliding pile project, the wastage was determinedof directly consumed materials adopting the observation method that conducted actual measurement at the construction site $[4,5]$; repeated usage method and amortization in equal installments method were used for the indirectly consumed materials.

\subsection{Data Processing Methods}

Productivity determination is the same as any physical quantity determination. It means that if there is any accidental error, a normal distribution is followed. The determination of construction productivity is to repeatedly measure a particular object, thus obtaining a set of sample data. However, this set of data is circumscribed, as it is only a random sample taken out from the productivity totality. The average value $\bar{x}$ of each sample is fluctuant, and there are also random variables which have their own distribution regularities, mean values and variances. If $x_{i}(i=1,2, \ldots, n)$ are mutually independent, their distributions are the same as population distribution, namely obeying a normal distribution [5].
When calculating, carrying out unbiased estimation for mean values and variances can make the sample's parameter results greatly approach the totality's parameter value, which can ensure the accuracy and reliability of data processing. The data handling for productivity measurements makes use of probabilistic evaluation method, which measures the percentage of workers who can reach or exceed a fixed productivity level. Meanwhile, it can also calculate the productivity quantity that a given percentage of workers can reach or exceed. The steps of probabilistic evaluation method are as follows:

\section{(1) To Delete Unreasonable Data}

The values that are obviously wrong or have egregious errors should be deleted when cleaning up the data. First, the data should be deleted in which deviation errors exist, completely resulting from the influence of human factors. Then according to the maximum and minimum limit values, as demonstrated in Eq. (1) and Eq. (2), the largely biased data should be deleted outside of the scope of both, resulting from the influence of construction factors.

$$
\begin{aligned}
& \operatorname{Lim}_{\text {max }}=\bar{X}+K\left(X_{\text {max }}-X_{\text {min }}\right) \\
& \operatorname{Lim}_{\text {min }}=\bar{X}-K\left(X_{\text {max }}-X_{\text {min }}\right)
\end{aligned}
$$

Where,

$\mathrm{Lim}_{\max }$----upper limit of measured productivity value allowed to be analyzed in the next step;

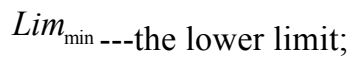

$K$---adjustment coefficient for properly handling the deviation percentage.

\section{(2) To Calculate the Mean Value $\bar{x}$, as Demonstrated in Eq.(3)}

$\bar{x}=(1 / n) \sum_{i=1}^{n} x_{i}$

According to the nature of mean value, the mean value $\bar{x}$ of samples' mean values $x_{i}$ is an unbiased estimator of population value. Thus, $\bar{x}$ can be used to estimate the true value $\mu$.

(3) To Calculate the Mean Square Deviation $s^{2}$, as Shown in Eq. (4) and Eq. (5):

In general, the mean square deviation $s^{2}$ is shown in

Eq. (4):

$s^{2}=(1 / n) \sum_{i=1}^{n}\left(x_{i}-\bar{x}\right)^{2}$

As the arithmetic mean value is used to replace the true value, so the result is biased. According to the deduced result of mathematical statistics formula [6], the unbiased standard deviation is shown in Eq. (5):

$v=\sqrt{[1 /(n-1)] \sum_{i=1}^{n}\left(x_{i}-\bar{x}\right)^{2}}$ 
This unbiased deviation $v$ is used as the estimator of the population deviation $\sigma$.

\section{(4) To Use a Normal Distribution to Determine the Productivity:}

Supposing that a set of sample data measured is $x_{1}, x_{2}$, $\ldots \ldots, x_{n}$, and the consumption value which makes $\omega \%$ workers reach or exceed sets is $x_{0}$. It can be seen from the probability function that it is a normal distribution, as shown in Eq. (5):

$\phi(\lambda)=(1 / \sqrt{2 \pi}) \int_{-\infty}^{\lambda_{0}} e^{-\lambda^{2} / 2} d \lambda$

Where, $\lambda=\frac{x-\bar{x}}{\sigma}, \lambda_{0}=$ value of $\lambda$; when $x$ takes the value of $x_{0}$. As $\phi\left(\lambda_{0}\right)=\omega \%$, the value of $\lambda_{0}$ can be obtained through calculation or look-up table. The corresponding relation between $x_{0}$ and $\lambda_{0}$ is shown in Eq. (6):

$x_{0}=\bar{x}+\lambda_{0} \sigma$

Thus, the average advanced value $x_{0}$ can be obtained, that $\omega \%$ workers may reach or exceed.
According to the method above, the corresponding average advanced values ( respectively calculated of the samples; then the average calculation is conducted with those values to arrive at the value $\bar{x}_{0}$, which is the productivity standard of the corresponding activity, namely consumption quota.

\section{DETERMINATION OF CONSTRUCTION PRODUCTIVITY}

\subsection{Typical Processes Extracting from the Anti-sliding Pile Construction of Xiluodu Hydropower Project}

The main operation of the anti-sliding pile construction seen in Fig. (1) includes surveying and setting out, construction preparation, holing, wall protection, reinforcing cage binding, formwork installing and dismounting, pilecore concrete grouting, top beam constructing [7], etc.

Among these, pile holing and wall protecting are in crossed progress and the construction procedure is illustrated in Fig. (2).

According to the above-mentioned construction procedure, typical process can be extracted from construction process of

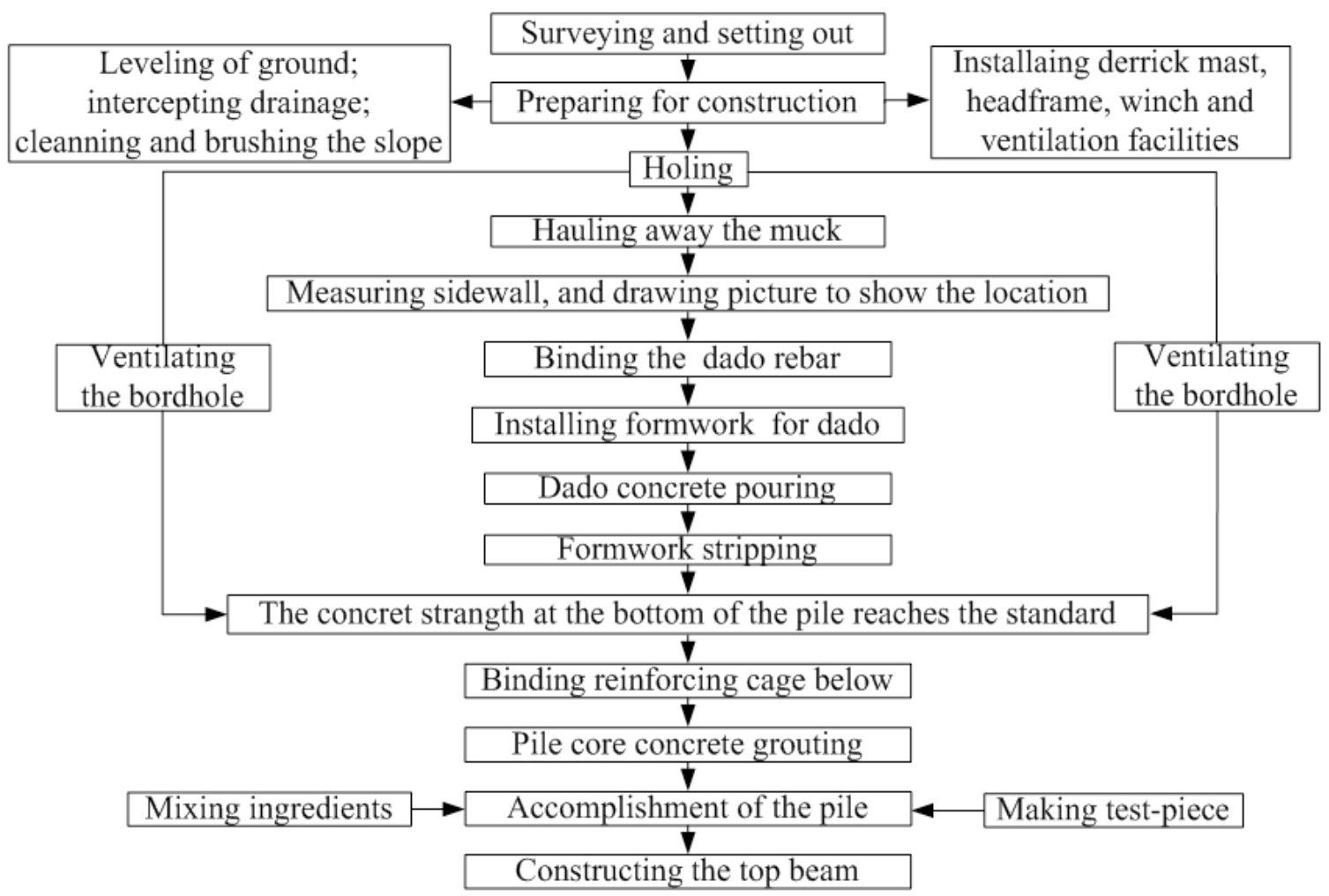

Fig. (1). Anti-sliding pile construction process.

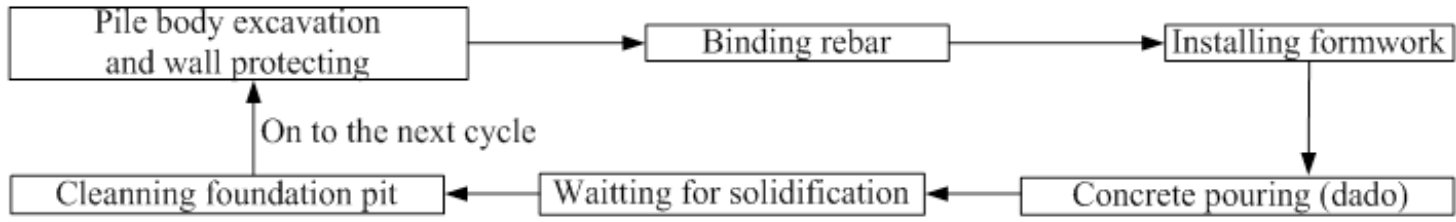

Fig. (2). Pile holing and wall protecting construction process. 
single anti-sliding pile: pile hole excavation and wall retaining $\rightarrow$ reinforcing cage binding $\rightarrow$ pile-core concrete grouting.

\subsection{Explanation for the Productivity Determination Mentioned Here}

This productivity determination work took $15^{\#}, 17^{\#}$ and $19^{\#}$ anti-sliding piles of Xiluodu project as the study objects.

The measurement method of manpower productivity mainly adopted realistic recording, timing manual hours by tracking and conducting actual measurement in accordance with the construction order, and meanwhile keeping track of the labor combination combined with field investigation method; the measurement of material productivity used a method combining observation and laboratory test; the measurement work of machine-team productivity also mainly employed realistic recording, conducting simultaneously themanpower productivity measurement. Besides, except for the parameters measured on-site, the determination of manpower consumption index should take into account the manpower magnitude difference coefficient valued $10 \%$; according to the difference of medium-sized machinery and large machinery, the determination of machine-team consumption index should take mechanical magnitude difference coefficient valued $10 \%$ to $15 \%$ into account $[8,9]$.

\subsection{Productivity Parameters Measurement}

\subsubsection{Parameters Measurement of Relevant Pile Holing and Wall Protecting}

The main works of anti-sliding pile holing and wall protecting were the excavation of soil layer and rock layer, and the concrete pouring of retaining wall at fore shaft, soil layer and rock layer.

The soil layer excavation was carried out mostly by manpower including digging and loading, the size of which was $3.6 \mathrm{~m} \times 4.6 \mathrm{~m}$. If there was hard soil, then pneumatic pick was used as auxiliary, and wind was offered with an electric air compressor $\left(3 \mathrm{~m}^{3} / \mathrm{min}\right)$. Muck was hoisted and hauled away by winding engine $(400 \mathrm{~kg})$. The rock layer excavation was carried out with drilling and blasting, the sectional dimension of which was $3 \mathrm{~m} \times 4 \mathrm{~m}$. As the working surface was small inside the rock, an air driving drilling machine could be used to drill, and an electric air compressor could be used to supply the air. The heights of piles' fore shafts above the original ground were different, but their sectional dimensions all were $5.6 \mathrm{~m} \times 4.6 \mathrm{~m}$.

The measurement of manpower productivity was conducted mainly targeting at the parameters of many crafts including the navvy, the craneman, the mechanic, the haulageman, the blaster, the driller, the welder, calculating the number of workers, effective working time, lost time, and so on. The measurement of material productivity usually aims at necessary consumption and loss amount of pyrotechnic material, rebar, formwork and concrete C30 used in the process of pile holing. The determination of machinery productivity is mainly aimed at effective time or loss of machinery equipment including winch, blender, concrete transport vehicle, electric welding machine, air driving drilling machine, air compressor, vibrator, etc.

\subsubsection{Parameter Measurement of Relevant Reinforcing Cage Binding}

In the back side of the anti-sliding pile, the $0.0 \sim 11.0 \mathrm{~m}$ area should be equipped with rebar $\varphi 36$ and $\varphi 32$ from the bottom, and should be bound together; rebar $\varphi 32$ should be used for the area above $11.0 \mathrm{~m}$. Three handling reinforcements $\varphi 25$ were respectively equipped on both the sides of the antisliding pile. The steel bars protection depth was $0.1 \mathrm{~m}$. Counting from the retaining wall side, there was $0.2 \mathrm{~m}$ distance between the second row of rebar and the first row of rebar.

The measurement of manpower productivity was mainly targeted at the parameters including the number of workers, effective working time and loss of rebar transport worker, rebar erecting worker (including rebar passing worker outside the hole, and rebar binding worker inside the hole). The measurement work of material productivity mainly involved rebar's necessary consumption and losses. The determination of machinery productivity mainly aimed at the effective and ineffective time of rebar transport vehicle and electric welding machine.

\subsubsection{Parameters Measurement of Relevant Pile-core Concrete Grouting}

The strength of pile-core concrete for Xiluodu project was C30; the slump was $0.07 \sim 0.09 \mathrm{~m}$; the water cement ratio was 0.49 . The concrete was carried to construction site by concrete mixing vehicle (RF150T), and layered vibration was conducted with immersion vibrator ZN-70.

The measurement of consumed manpower was mainly targeted at the parameters including the number of workers, effective working time and losses of haulageman, pourer and vibrating worker. The objective of the measurement of consumed material included the necessary consumption and loss of concrete C30. The measurement of consumed machinery shift was mainly conducted aiming at effective and ineffective time of the concrete mixing carrier and the vibrorammer.

\subsection{Results of the Productivity Determination}

Through the measurement methods above, the basic productivity data of the activities were separately obtained, in the construction process of $15^{\#} 、 17^{\#} 、 19^{\#}$ anti-sliding piles of Xiluodu project. By probabilistic evaluation method, the corresponding average advanced values $\left(x_{0}{ }^{(1)}, x_{0}{ }^{(2)}, x_{0}{ }^{(3)}\right)$ that $95 \%$ workers can reach or exceed were alsoe acquired, thus obtaining the consumption quota. Table 1 shows the final measurement results obtained through the methods and procedures above.

\section{CONCLUSION}

The productivity measurement work for the anti-sliding pile of Xiluodu Hydropower Project started from the determination of measuring methods moving on to the parameter measurement of relevant construction processes, 
Table 1. Measurement results of construction productivity of the anti-sliding pile.

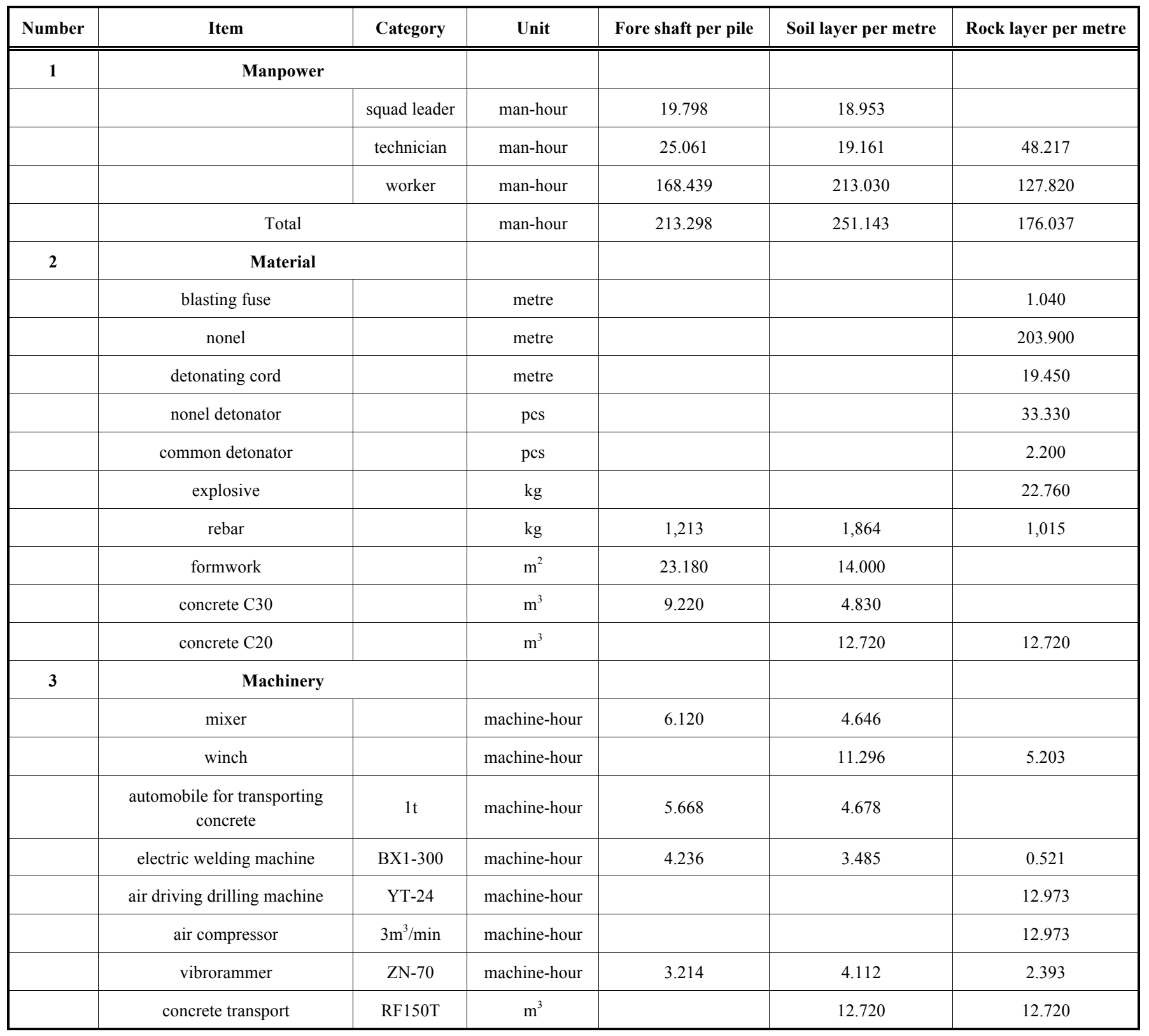

and then to the processing and summarizing of the obtained original data, thus finally forming the consumption quota. The whole process is in line with the attitude of "seek truth from facts" and is rigorously scientific. The determination of construction productivity mentioned in this paper adopted probabilistic evaluation method and controlled the fixed productivity level around $95 \%$, which conforms to the compilation principle and fully reflects the practical significance of construction productivity. Unfortunately, there had been no existing productivity standard or pricing basis of the anti-sliding pile in the hydropower industry before the measurement method mentioned here was accomplished. Accordingly, this measurement may provide referential experience for management and control works of similar projects in future, such as construction schedule arrangement, resources disposition and so on; in addition, combining basic unit prices stipulated by state or local government, market price levels and relevant policies, the corresponding cost quota can be worked out, which may provide scientific basis for the evaluation of the similar types of projects in the construction industry.

\section{CONFLICT OF INTEREST}

The authors confirm that this article content has no conflict of interest.

\section{ACKNOWLEDGEMENTS}

The authors wish to thank the Educational Commission of Hubei Province for research grants under contract D20141208. And also to thank the Scientific Research Foundation of China Three Gorges University for research grants under contract KJ2013B014 and KJ2013B006. 


\section{REFERENCES}

[1] G. Zou and S. Chen, "A design method of stabilizing piles and its optimized numerical mode", Chinese Journal of Geotechnical Engineering, vol. 25, no. 1, pp. 11-17, 2003.

[2] G. Liu, "Internal Force Calculation and Experimental Study of The Bridge Double Piles Structure in High- Steep Transverse Slope", M.S. thesis, Hunan University, Changsha, Hunan Province in China, 2011

[3] Y. Lin, H. Yu, and Z. Shi. "Anti-slide pile reinforcement mechanism and the study on its application to the landslide treatment," Science and Technology Innovation Herald, vol. 30. no. 10, p. 42.2011

[4] J. Chang, "Study on the comprehensive application of basic methods in the process of complementary quota formulation,"
China Science and Technology Review, vol. 10, no. 8. pp. 41-42, 2009.

[5] Q. Liu, "Discussion about the establishment method of enterprise quota," Project Management, vol. 8, pp. 36-37, 2008.

[6] X. Chen, and G. Ni., "Mathematical Statistics Course", Shanghai Scientific and Technical Publishers, Shanghai in China, 1988.

[7] W. Wang, "On the construction of anti-sliding pile", Copper Engineering, vol. 3, pp. 82-84. 2007

[8] L. Cheng, and Z. Wang, "Analysis on the application of physical flow method to hydropower project cost," Yunnan Water Power, vol. 25 , no. 4 , pp. $27-28,2009$.

[9] Z. Xu, "Introduction to the establishment of engineering budget quota," Science and Technology Innovation Herald, vol. 8, pp. 3435,2008 .

(C) Zhiding et al.; Licensee Bentham Open.

This is an open access article licensed under the terms of the Creative Commons Attribution Non-Commercial License (http://creativecommons.org/licenses/ by-nc/4.0/) which permits unrestricted, non-commercial use, distribution and reproduction in any medium, provided the work is properly cited. 